\title{
Injury Outcomes in Elderly Patients Admitted at an Urban African Hospital
}

\author{
Hassan Saidi ${ }^{*}$, Benson Mutiso ${ }^{2}$ \\ ${ }^{1}$ Department of Human Anatomy, University of Nairobi, Nairobi, Kenya \\ ${ }^{2}$ Embu Provincial General Hospital, Embu, Kenya \\ Email: ${ }^{*}$ hsaidi@uonbi.ac.ke
}

Received January 12, 2013; revised February 15, 2013; accepted February 23, 2013

Copyright (C) 2013 Hassan Saidi, Benson Mutiso. This is an open access article distributed under the Creative Commons Attribution License, which permits unrestricted use, distribution, and reproduction in any medium, provided the original work is properly cited.

\begin{abstract}
Background: Elderly patients have worse outcomes for similar severity when compared to younger trauma patients. Elderly patients form smaller proportions of the trauma population in the developing world in comparison to high income countries. Due to limited data capabilities, elderly trauma has been infrequently studied. Objective: To describe the common injuries that afflict elderly trauma patients associated resource utilization and the determinants of outcome in Kenyan urban hospital. Methods: Seventy two patients aged 60 years and older admitted for trauma from diverse mechanisms, were recruited over a period of one year (November 2009-December 2010). Data on the specific mechanism and type of injury, age, sex, intensive care unit (ICU) use, hospital length of stay, and cost were recorded. Survivors and those who died during admission were compared to determine associated factors. Elderly patients were also compared to younger trauma patients to determine significant group peculiarities using X2 analysis or Fisher's exact test as appropriate. Results: Elderly trauma cases (mean age $70.5+9.1$ years) formed $4.5 \%$ of all trauma admissions during the study period. The intent was accidental in $84.7 \%$ of cases. The predominant mechanisms of injury were traffic (44.4\%) and falls (41.7\%). Females comprised $41.7 \%$ of all patients and lower limb fractures predominated (54.9\%). The average injury severity score was 7.82 +4.4. (median 9.0). The proportion admitted to the ICU was $6 \%$. The median length of hospital stay was 24 days, cost of treatment Kshs. 27,153 Kenya shillings and overall hospital mortality rate was $13.9 \%$ ( $25 \%$ for ISS $>15)$. Only gender and head injury were predictors of mortality. Conclusions: Traffic and falls are the predominant mechanisms in geriatric trauma in Kenya. Unique features of geriatric trauma are higher female involvement, prolonged length of hospital stay and fewer predictors of mortality compared to younger patients.
\end{abstract}

Keywords: Elderly Trauma; Outcomes; Africa

\section{Introduction}

The burden of trauma and its associated treatment is a global challenge. Because trauma mostly afflicts the young, more emphasis and resources have understandably, been extended to the younger trauma patients $[1,2]$. But, for similar mechanisms, older patients sustain more severe injuries and pose more challenges. At this extreme of age, co-morbid conditions are frequent, blood and volume losses are tolerated poorly and requirements for medical and surgical resources disproportionately greater [3]. In high income countries where population health indices are better, people are living longer. An increasing number of elderly trauma has demanded a response in terms of geriatric trauma studies and development of geriatric trauma care units [4].

\footnotetext{
"Corresponding author.
}

The published data on geriatric trauma in Africa is scarce. According to the CDC, the leading causes of traumatic geriatric deaths are motor vehicles, firearms and poisonings and older individuals are twice as likely to die from their injuries as younger people [5]. This study evaluated the common mechanisms, patterns of injury and outcomes associated with elderly trauma patients at the Kenyatta National Hospital.

\section{Methods}

This descriptive review of prospectively collected data was undertaken at the Kenyatta National hospital, a 2000 bed teaching and referral hospital in Nairobi, Kenya. The catchment population is about three million inhabitants. Seventy two patients aged 60 years and older and admitted after trauma between November 2009 and December 2010 were analyzed. 
Data abstracted included age, sex, mechanism of injury, injury type, Accident and emergency room disposition, resource utilization and hospital mortality. Injuries were classified into the following categories: falls, motor vehicle collision, assault, gunshot injuries and others. We used descriptive statistics to analyze the data. Direct cost to the patient based on the hospital billing system was in Kenya shillings ( $86 \mathrm{Kshs}$ to the USD). The demographic, injury and outcome characteristics of the elderly trauma patients were compared to younger patients, admitted during the study period, to determine significant differences. Survivors and non-survivors in the geriatric group were compared to reveal the factors associated with survival. Means were tested using the Student's t test while proportions were stated using Chi square or Fischer's exact test as appropriate. Approval for this research was obtained from the hospital's ethics committee.

\section{Results}

\subsection{Socio-Demographic Characteristics}

Seventy two out of 1594 trauma admissions during the study period were patients aged 60 years and older. They formed $4.5 \%$ of all trauma admissions. The average age was $71.7 \pm 9.9$ years (range $60-98$ years). The intent was accidental in $84.7 \%$ of cases. Males (58.3\%) more than females $(41.7 \%)$ were involved. Most had not attended school beyond the primary level (Table 1).

\subsection{Injury Characteristics}

Injuries due to traffic (44.4\%) and falls (41.7\%) accounted for majority of admissions (Figure 1).

Pedestrians (61.3\%) were the most common road users injured. The predominant anatomical region affected was the extremity $(63.9 \%)$. Injuries to the head/neck constituted $26.4 \%$ of all injuries. Specific injuries most frequently recorded were fractures of the femur $(34.7 \%)$, fractures of the lower limb other than femur (19.4\%) and head injuries (11.1\%) (Table 2). The average injury score on admission was $7.82 \pm 4.4$. (range of 1 - 27).

\section{Outcomes}

From the accident and emergency unit, four patients were disposed to the ICU, one direct to the Operation Room and the rest (93.1\%) to the ward. About one half (48.6\%) and one fifth $(18.9 \%)$ of the patients required surgical intervention and blood transfusion respectively.

There were ten $(13.9 \%)$ deaths within two weeks of hospitalization. Forty seven percent of patients were discharged home fully recovered while 17 (23.7\%) were discharged with various degrees of disabilities. The length of hospital stay averaged $34.64+32.8$ days (median 24) while the cost of treatment was Kshs. 37,884 + 38,477 (median Kshs. 27,153).

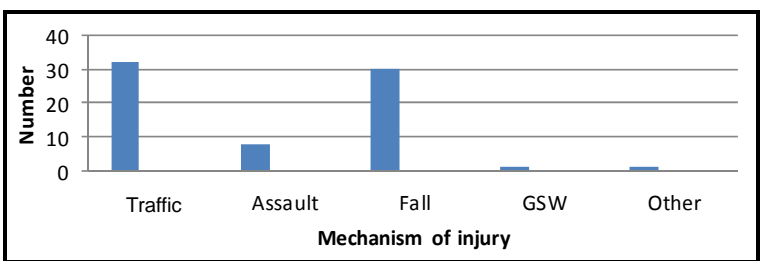

Figure 1. Mechanisms of injury in elderly patients at KNH.

The ISS of patients who died was 8.9 while that of survivors was $7.6(p=0.408)$. There was also no significant difference in the means of their ages. The proportions of traffic injury (15.6\% versus $12.5 \%$, p 0.703$)$, ISS $>15(25 \%$ versus $12.7 \%, \mathrm{p} 0.313)$, transfusion $(18.5 \%$ versus $16.3 \%, \mathrm{p} 1$ ) were not significantly different between survivors and non-survivors. Survivors however required more surgical procedures $(21.1 \%$ versus $5.9 \%$, p $0.09)$ than non-survivors. There were also more males (21.4\% versus $3.3 \%$, p 0.04$)$ and head injuries (50\% versus $9.5 \%$ ) in the mortality group than among survivors.

Compared to younger patients, trauma in patients 60 years and older involved more unintentional trauma ( $\mathrm{p}$ $0.039)$, transfer-ins $(0.01)$, females $(\mathrm{p}<0.001)$, non-traffic trauma (0.002) and head injuries (0.046). As noted, the two age groups were similar for injury severity and rates of ICU admission, surgery and transfusion (Table 3) but older patients were twice as likely to die after a trauma admission as compared to younger patients ( $p$ value $<0.001$, OR 2.1).

\section{Discussion}

This study has revealed that elderly trauma patients comprise only $4.5 \%$ of all trauma admissions. It documents the patterns of injuries and patient outcomes as seen from a developing country perspective, where resources to manage the challenges posed are not always available. This result is inconsistent with published data from high income countries where elderly patients may form up to $30 \%$ of the trauma population admitted [3]. In the United states the average life expectancy rose from 47 in the 1990s to 77 years in 2000 [6] The life expectancy in Kenya today is akin to America's, 30 years ago. Because the burden of trauma in the elderly is several times smaller when compared to developed countries, there is a risk they may be ignored. The life expectancy in Kenya is reportedly increasing (Daily Nation, August, 2012) and surgeons will increasingly be involved in the care of elderly patients who are known to have higher complications and mortality rates than younger patients but with limited resources.

Majority of the admissions in this study followed traffic collisions $(44.4 \%)$ and falls $(41 \%)$. Available ac counts from outside Africa indicate that the most common reason for trauma in the elderly is a fall [3,7-11]. In the Canadian study by Gowing et al. [3] for example, fall 
Table 1. Socio-democratic characteristics of elderly trauma patients at KNH.

\begin{tabular}{|c|c|c|c|}
\hline Characteristic & & Number & $\%$ \\
\hline \multirow[t]{2}{*}{ Gender } & Male & 42 & 58.3 \\
\hline & Female & 30 & 41.7 \\
\hline \multirow[t]{3}{*}{ Admission status } & Direct from scene & 22 & 30.6 \\
\hline & Referral & 41 & 56.9 \\
\hline & No detail & 9 & 12.5 \\
\hline \multirow[t]{4}{*}{ Intent } & Unintentional & 61 & 84.7 \\
\hline & Homicide & 9 & 12.5 \\
\hline & Suicide & 1 & 1.4 \\
\hline & Missing & 1 & 1.4 \\
\hline \multirow[t]{5}{*}{ Education } & Nil & 25 & 34.7 \\
\hline & Primary & 22 & 30.6 \\
\hline & Secondary & 11 & 15.3 \\
\hline & College/university & 1 & 18.1 \\
\hline & Unknown & 13 & 6.9 \\
\hline \multirow[t]{5}{*}{ Occupation } & Housewife & 5 & 6.9 \\
\hline & Farmer & 14 & 19.4 \\
\hline & Formal employment & 3 & 4.2 \\
\hline & Informal employ & 13 & 18.1 \\
\hline & Missing & 9 & 12.5 \\
\hline
\end{tabular}

Table 2. Injury characteristics for elderly patients at KNH.

\begin{tabular}{|c|c|c|c|}
\hline Characteristic & & Number & $\%$ \\
\hline \multirow[t]{3}{*}{ MV/Motorcycle } & Driver/rider & 3 & 4.2 \\
\hline & Occupant/Passenger & 9 & 29.1 \\
\hline & Pedestrian & 19 & 61.3 \\
\hline \multirow[t]{4}{*}{ Principal region } & Head/neck & 19 & 26.4 \\
\hline & Chest/abdomen & 2 & 2.8 \\
\hline & Spine & 5 & 6.9 \\
\hline & Extremity & 46 & 63.9 \\
\hline \multirow[t]{2}{*}{ Fall } & Same level & 24 & 75.0 \\
\hline & Fall from height & 8 & 25.0 \\
\hline \multirow[t]{9}{*}{ Specific injuries } & Head injury & 8 & 11.1 \\
\hline & Spine injury & 5 & 6.9 \\
\hline & Lower limb fracture & 14 & 19.4 \\
\hline & Femur fracture & 25 & 34.7 \\
\hline & Abdomen/thoracic injury & 2 & 2.8 \\
\hline & Facial/orbital & 3 & 4.2 \\
\hline & Upper limb fracture & 3 & 4.2 \\
\hline & Multisystem & 7 & 9.7 \\
\hline & Soft tissue injury & 4 & 5.6 \\
\hline
\end{tabular}

MV: Motor vehicle.

was the predominant mechanism in $64 \%$ of cases. The predominant road user injured in this study was a pedes- trian while $75 \%$ of the falls were same level falls. This is consistent with published literature. Low-level falls from 
Table 3. Comparison of young and old trauma patients at KNH.

\begin{tabular}{|c|c|c|c|}
\hline & Age $<60$ years & Age $\geq 60$ years & (P value) \\
\hline Male & 1251 & 42 & $<0.001$ \\
\hline Female & $253(16.8 \%)$ & $30(41.7 \%)$ & \\
\hline Unintentional & 1140 & 61 & 0.04 \\
\hline Intentional injury & $377(24.9 \%)$ & $10(14.1 \%)$ & \\
\hline Traffic mechanism & 951 & 32 & 0.002 \\
\hline Non-traffic & $571(37.5 \%)$ & $40(55.6 \%)$ & \\
\hline Disposed to ward & 1380 & 67 & 0.49 \\
\hline Disposed to ICU/OR & $142(9.3 \%)$ & $5(6.9 \%)$ & \\
\hline Head/neck region & $579(38 \%)$ & $19(26.4 \%)$ & 0.046 \\
\hline Other body regions & 943 & 53 & \\
\hline Surgery done & 704 & 34 & 0.9 \\
\hline No surgery & $783(52.7 \%)$ & $38(52.8 \%)$ & \\
\hline ISS $<16$ & 1343 & 63 & 0.88 \\
\hline ISS $\geq 16$ & $161(10.7 \%)$ & $8(11.3 \%)$ & \\
\hline Direct from scene & 690 & 22 & 0.01 \\
\hline Transfer-in & $651(48.5 \%)$ & $41(65.1 \%)$ & \\
\hline Alive at 2 weeks & 1370 & 62 & 0.026 \\
\hline Dead at 2 weeks & $102(6.9 \%)$ & $10(13.9 \%)$ & \\
\hline
\end{tabular}

standing heights are caused by age related alterations in the body, limb strength and balance. Other documented risk factors include female gender, previous fall, psychotropic drug use, and arthritis. The increased risk of pedestrian injury amongst elderly is occasioned by frailty at walking, impaired reflexes, vision, hearing and movements $[12,13]$.

Fractures to the limbs were the most frequent injuries. Minor injuries easily break the relatively weakened bones in the elderly. This predominance of limb factures explains the overall moderate injury severity score in the present study, at variance with Western trauma series that show much higher severity levels for elderly trauma admissions [3]. Variations in referral practices may be the basis for the differences in acuity level between our patients and reports from trauma centers. Kenyatta National hospital receives majority of injuries that occur in the city of Nairobi, treats all levels of injury and is often overwhelmed with the management of minor injuries. In the West, lower acuity trauma is handled at a lower level facility leaving level 1 trauma centers to deal with complex trauma. Our data suggest that geriatric patients admitted as transfer-ins sustained more severe injuries. The establishment of first and second level hospitals within a Nairobi trauma system may see an evolution where $\mathrm{KNH}$ is left to handle more complex and severe trauma.

The prolonged hospital stays for geriatric trauma at $\mathrm{KNH}$ are unique with reference to series from mature trauma systems. By two weeks after admission, majority of the patients were still in the ward. Although elderly trauma is associated with longer hospital stays, incurs higher overall hospital charges, and require longer period of rehabilitation, the duration in this study is excessive. The reasons for this were not explored. Older patients have more frequent comorbid illnesses that impair their recovery from injury, are physiologically challenged and incur more complications. Whether this excess hospitalization period is informed by unique care protocols employed at this hospital is a subject to be studied.

The hospital mortality post-trauma was $13 \%$. This was doubled the rate in younger patients. Although the group studied sustained low acuity trauma, our results still corroborate the general view that older individuals are more likely to die from their injuries as younger people. Of the factors tested for association with mortality in this study, only gender, head injury and 'no surgery' were significant. The injury, patient and hospital factors responsible for the increased mortality in geriatric trauma have not been fully clarified. There is controversy on whether adverse outcomes in geriatric trauma can be predicted by patient age, ISS, RTS, mechanism of injury, pre-existing conditions, occurrence of complications and ICU use $[3,14]$. Available studies show conflicting results on the effect of age on survival in geriatric trauma [15-18]. In the study by Perdue et al. involving 448 patients, 65 years and older, age was significantly predictive of mortality [17] while in the study by Knudson et al., involving 852 patients, the effect of age was similar between sur- 
viving and non-surviving geriatric trauma patients [18].

Injury Severity Score (ISS) is a well researched anatomic score. Like the influence of age on geriatric mortality, some authors have found it to be a strong adverse outcome predictor in geriatric trauma $[18,19]$ while others have failed to show any influence on mortality $[20,21]$.

The association of geriatric mortality and head injury in this study is consistent with a number of previous reports that demonstrate that "Low" admission GCS is associated with poor outcomes in elderly head-injured patients [22-24]. The explanation for the higher mortality in head injured geriatric patients lies in the changes that occur to the brain with age including, size, weight and reduction in cerebrovascular autoregulation [25].

This study had limitations. The proportion of very severe and critical injuries was low. Therefore the mortality analysis may only be applicable to capitals of developing countries and not high income nations. Comorbid illnesses were not sought. Majority of studies demonstrate that the presence of pre-existing medical conditions (PEC's) adversely affects outcome [26]. Further, we did not explore the contribution of complications that occurred during treatment as this also has a bearing on outcomes including mortality and prolonged lengths of hospital stay. All the same our study provides important insights into the characteristics of geriatric trauma in an African country setting. Trauma in the elderly forms less than $5 \%$ of the injury burden but the associated mortality and resource utilization is similar or higher than that in the young. The long hospital stays and predominance of orthopedic injuries and association of adverse outcomes with neurotrauma call for a trauma care that targets their specific early interventions.

\section{REFERENCES}

[1] H. R. Champion, W. S. Copes, D. Buyer, M. E. Flanagan, L. Bain and W. J. Sacco, "Major Trauma in Geriatric Patients," American Journal of Public Health, Vol. 79, No. 9, 1989, pp. 1278-1282. doi:10.2105/AJPH.79.9.1278

[2] M. T. Aschkenasy and T. C. Rothenhaus, "Trauma and Falls in the Elderly," Emergency Medicine Clinics of North America, Vol. 24, No. 2, 2006, pp. 413-432. doi:10.1016/j.emc.2006.01.005

[3] R. Gowing and M. K. Jain, "Injury Patterns and Outcomes Associated with Elderly Trauma in Kingston, Ontario," Canadian Journal of Surgery, Vol. 50, No. 6, 2007, pp. 437-444.

[4] A. J. Mangram, G. D. Mitchel, V. K. Shifflette, M. Lorenzo, M. S. Twitt, A. Goel, M. A. Lyons, D. J. Nicholl and E. L. Dunn, "Geriatric Trauma Service: A One-Year Experience," The Journal of Trauma and Acute Care Surgery, Vol. 72, No. 1, 2012, pp. 119-122.

[5] N. R. Sahyoun, H. Lentzner, D. Hoyert and K. N. Robinson, "Trends in Causes of Death among the Elderly,"
Centers for Disease Control and Prevention, 2001.

[6] J. Day, "Population Projections of the United States by Age, Sex, Race, and Hispanic Origin: 1995 to 2050," US Bureau of the Census, Washington DC, 1996, pp. 251130.

[7] D. W. Spaite, E. A. Criss, T. D. Valenzuela, H. W. Meislin and J. Ross, "Geriatric Injury: An Analysis of PreHospital Demographics, Mechanisms, and Patterns," Annals of Emergency Medicine, Vol. 19, No. 12, 1990, pp. 1418-1421. doi:10.1016/S0196-0644(05)82611-3

[8] W. C. Graafmans, M. E. Ooms, H. M. Hofstee, P. D. Bezemer, L. M. Bouter and P. Lips, "Falls in the Elderly: A Prospective Study of Risk Factors and Risk Profiles," American Journal of Epidemiology, Vol. 143, No. 11, 1996, pp. 1129-1136.

doi:10.1093/oxfordjournals.aje.a008690

[9] A. J. Campbell, M. J. Borrie and G. F. Spears, "Risk Factors for Falls in Community-Based Prospective Study of People 70 Years and Older," The Journals of Gerontology, Vol. 44, No. 4, 1989, pp. 112-117. doi:10.1093/geronj/44.4.M112

[10] V. T. Valley, H. Hepp, D. J. DeBehnke, S. W. Lawrence and C. Abrahamian, "A Profile of Geriatric Trauma in Southeastern Wisconsin," Wisconsin Medical Journal, Vol. 93, No. 4, 1994, pp. 165-168.

[11] J. J. Tepas, H. C. Veldenz, L. Lottenberg, L. A. Ronig, A. Pearman, B. Hamilton, R. E. Slevinski and D. J. Vllani, "Elderly Injury: A Profile of Trauma Experience in the Sunshine (Retirement) State," The Journal of Trauma, Vol. 48, No. 4, 2000, pp. 581-584. doi:10.1097/00005373-200004000-00001

[12] G. F. McCoy, R. A. Johnstone and R. B. Duthie, "Injury to the Elderly in Road Traffic Accidents," The Journal of Trauma, Vol. 29, No. 4, 1989, pp. 494-497. doi:10.1097/00005373-198904000-00013

[13] D. P. Sklar, G. B. Demarest and P. McFeeley, "Increased Pedestrian Mortality among the Elderly," The American Journal of Emergency Medicine, Vol. 7, No. 4, 1989, pp. 387-390. doi:10.1016/0735-6757(89)90044-2

[14] K. Sugimoto, T. Aruga, M. Hirata and M. Shindo, "Geriatric Trauma Patients at a Suburban Level-1 Trauma Center in Japan," Prehospital and Disaster Medicine, Vol. 14, No. 3, 1999, pp. 79-83.

[15] J. V. Pellicane, K. Byrne and E. J. DeMaria, "Preventable Complications and Death from Multiple Organ Failure among Geriatric Trauma Victims," The Journal of Trauma, Vol. 33, No. 3, 1992, pp. 440-444. doi:10.1097/00005373-199209000-00018

[16] T. Osler, K. Hales, B. Baack, K. Bear, K. His, D. pathak and G. Demarest, "Trauma in the Elderly," The American Journal of Surgery, Vol. 156, No. 6, 1988, pp. 537-543. doi:10.1016/S0002-9610(88)80548-8

[17] P. W. Perdue, D. D. Watts, C. R. Kaufmann and A. L. Trask, "Differences in Mortality between Elderly and Younger Adult Trauma Patients: Geriatric Status Increases Risk of Delayed Death," The Journal of Trauma, Vol. 45, No. 4, 1998, pp. 805-810.

doi:10.1097/00005373-199810000-00034 
[18] M. M. Knudson, J. Lieberman, J. A. J. Morris, B. M. Cushing and H. A. Stubbs, "Mortality Factors in Geriatric Blunt Trauma Patients," Archives of Surgery, Vol. 129, No. 4, 1994, pp. 448-453. doi:10.1001/archsurg.1994.01420280126017

[19] J. A. J. Morris, E. J. MacKenzie, A. M. Damiano and S. M. Bass, "Mortality in Trauma Patients: The Interaction between Host Factors and Severity," The Journal of Trauma, Vol. 30, No. 12, 1990, pp. 1476-1482. doi:10.1097/00005373-199012000-00006

[20] P. L. Broos, A. D’Hoore, P. Vanderschot, P. M. Rommens and K. H. Stappaerts, "Multiple Trauma in Elderly Patients. Factors influencing Outcome: Importance of Aggressive Care," Injury, Vol. 24, No. 6, 1993, pp. 365368. doi:10.1016/0020-1383(93)90096-O

[21] F. D. Battistella, A. M. Din and L. Perez, "Trauma Patients 75 Years and Older: Long-Term Follow-Up Results Justify Aggressive Management," The Journal of Trauma, Vol. 44, No. 4, 1998, pp. 618-623. doi:10.1097/00005373-199804000-00010

[22] F. Reuter, "Traumatic Intracranial Hemorrhages in Eld- erly People," Advances in Neurosurgery, Vol. 17, 1989, pp. 43-48. doi:10.1007/978-3-642-74279-8 6

[23] C. J. Rozzelle, J. L. Wofford and C. L. Branch, "Predictors of Hospital Mortality in Older Patients with Subdural Hematoma," Journal of the American Geriatrics Society, Vol. 43, No. 3, 1995, pp. 240-244.

[24] S. Kilaru, J. Garb, T. Emhoff, V. Fiallo, B. Simon, T. Swiencicki and K. F. Lee, "Long-Term Functional Status and Mortality of Elderly Patients with Severe Closed Head Injuries," The Journal of Trauma, Vol. 41, No. 6, 1996, pp. 957-963.

[25] M. Czosnyka, M. Balestreri, L. Steiner, P. Smielewski, P. J. Hutchinson, B. Matta and J. D. Packard, "Age, Intracranial Pressure, Autoregulation, and Outcome after Brain Trauma," Journal of Neurosurgery, Vol. 102, No. 3, 2005, pp. 450-454.

[26] M. D. Taylor, J. K. Tracy, W. Meeyer, M. Pasquale and L. M. Napolitano, "Trauma in the Elderly: Intensive Care Unit Resource Use and Outcome," The Journal of Trauma, Vol. 53, No. 3, 2002, pp. 407-414. 